\title{
University of New England
}

\section{DUNE: DigitalUNE}

$4-1986$

\section{Prediction of Methylphenidate (Ritalin) Responsiveness Through Sensory Integrative Testing}

Judith Giencke Kimball

University of New England, jkimball@une.edu

Follow this and additional works at: http://dune.une.edu/ot_facpubs

Part of the Occupational Therapy Commons, and the Pharmacy and Pharmaceutical Sciences Commons

\section{Recommended Citation}

Kimball, Judith Giencke, "Prediction of Methylphenidate (Ritalin) Responsiveness Through Sensory Integrative Testing" (1986). Occupational Therapy Faculty Publications. Paper 2.

http://dune.une.edu/ot_facpubs/2 


\title{
Prediction of Methylphenidate (Ritalin) Responsiveness Through Sensory Integrative Testing
}

\author{
(hyperactivity, motor; sensory integration; vestibular reactivity)
}

\author{
Judith Giencke Kimball
}

Seventeen children previously judged to be good or poor responders to methylphenidate (Ritalin) were tested on sensory integrative measures while in the off-drug state. The tester was unaware of the children's drug response category. Results showed that children who were poor responders to Ritalin showed prolonged scores on and an adverse reaction to the Southern California Postrotary Nystagmus Test and had poorer equilibrium reactions and lower double tactile stimuli scores than the children judged good responders to Ritalin. These findings suggest that it might be possible to identify good and poor responders to Ritalin before the medication is given, something not previously thought possible. The current method for making this distinction is through a drug trial. These findings also indicate that there are at least two discernible types of hyperactivity associated with attention deficit disorders $(A D D)$ that are theoretically related to differences in vestibular processing: one related to underaroused or overinhibited lower brain centers, and another related to deficient inhibition from higher brain centers. The good responders to Ritalin appear to be the underaroused group, the same population that responds to sensory integrative occupational therapy techniques. This implies that perhaps occupational therapy could be used to reduce the medication needs of these children.

$T_{1}$ o date, no diagnostic test battery has been established as a valid predictor of stimulant response in treating the hyperactivity associated with attention deficit disorders (ADD). Therefore, medical practitioners have had to rely on the child's response to the drug to establish its effectiveness. This procedure often leads to unnecessary problems for children and their parents. It also reflects the general lack of knowledge about drug effects on humans, especially ADD children with hyperactivity.

Sroufe's (1) assertion is accepted by most investigators in the field of learning disabilities. He states "that there is no evidence that more than a minority of the large number of children currently labeled as 'hyperactive,' 'hyperkinetic' or 'minimal brain dysfunction syndrome' have underlying CNS [central nervous system] impairment or a medical history conducive to brain damage. In fact, it seems clear that there is a great heterogeneity in this group of children and that they probably do not make up a medical entity at all" (p. 390).

Research in learning disabilities has indicated that the hyperactive child's main problem is impaired attention; therefore there has been a shift to the term $A D D$, with and without hyperactivity, to replace the term hyperactivity. Consistent with this view, research on drug effectiveness with children with ADD has focused on tasks requiring attention. For example, investigators have used paired associate learning (PAL) tasks, the Wechsler Intelligence Scale for Children (WISC) Digit Symbol, or Frostig Figure Ground tests (2, J. Swanson, personal communication, November 1979 and February 1980). This research unfortunately failed to demonstrate positive effects of

Judith Giencke Kimball, PhD, OTR, is Associate Professor and Director, Division of Occupational Therapy, University of New England, Biddeford, ME 04005. She is also a faculty member of Sensory Integration International, Torrance, CA 90501. 
drugs on problem solving, nonrote learning, reasoning, school achievement, or changes on intelligence quotient (IQ) or achievement tests (1).

In addition to attentional problems, perceptual and/or motor difficulties have also been noted by teachers and other professionals working with ADD children. Programs were designed to ameliorate these problems $(3,4)$. However, evaluation studies of these programs indicate that academic achievement was not influenced significantly (5-7).

Although improvement in reading, spelling, handwriting, and mathematics are the major goals of educators, it would appear that an improvement of these skills in the ADD child does not lie in the domain of interventions focusing on attentional and perceptual motor skills. For example, inefficiencies in processing visual and auditory information, often considered to be the basis of perceptual problems, have not been improved significantly through specific skill training (8). Nor have there been improvements in the coordination problems that often accompany these perceptual processing deficits (8). These approaches have not addressed the underlying causes of learning problems, which is necessary in order to develop appropriate interventions.

\section{Review of Literature}

In the early 1960s, Ayres (9-14) began researching the influence of the sensory systems, which, in addition to vision and audition, contribute to motor and perceptual development. She proposed that tactile, proprioceptive, and especially vestibular system inputs contribute to the development of good motor, perceptual, and language skills.
Ayres' factor analytic studies have consistently identified tactile, proprioceptive, and vestibular processing problems as primary to the deficits of learning disabled and hyperactive children. On the basis of this research, she developed the Southern California Sensory Integration Tests (SCSITs), the Southern California Postrotary Nystagmus Test (SCPNT), and related clinical observations. Based on testing results, differential sensory integration profiles were developed that included measures of the vestibular, proprioceptive, and tactile sensory modalities. Subsequent efforts to develop treatment interventions based on these profiles were successful $(14,15)$.

It is hypothesized that these sensory integrative profiles can be used to differentiate between those children who respond favorably and those who respond adversely to medication for hyperactivity. If differences in drug responsiveness can be correlated with differences in sensory integrative profiles, it may be possible to predict, before a stimulant medication is given, whether a given child will respond favorably or unfavorably to the drug. The ability to predict drug

\section{The ability to predict drug responsiveness prior to administration would spare poor responders a needless drug trial and could affect the occupational therapy treatment of these children.}

responsiveness prior to administration would spare poor responders a needless drug trial and could affect the occupational therapy treatment of these children.
Children taking stimulant drugs have long been divided into good and poor response categories by their behavioral manifestations while on drugs. A more specific differentiation of children by response categories has been done at the Hospital for Sick Children, Toronto, Ontario, where Swanson and associates (16) have used a $\mathrm{PAL}$ procedure to evaluate more than 400 children referred with symptoms of hyperactivity.

While conducting studies, Swanson, Kinsbourne, and their colleagues $(2,16-18)$ consistently found that $30 \%$ of the patients in their samples were adverse responders even though they carefully selected patients on the basis of "hyperactive" behavior. In their 1978 study, Swanson and associates (17) stated that these poor responders best fit the American Psychiatric Association's Diagnostic and Statistical Manual of Mental Disorders (DSM) Subgroup 308.2, "overanxious," because all children labeled in this way were adverse responders. Some adverse responders, however, were found in other categories. Therefore, all "hyperactive" children are not the same, although the underlying reason for the differences is not clear.

Swanson and associates (17) concluded in their 1978 study that the same symptoms of "hyperactivity" occur in "at least two quite distinct subpopulations, and that the children in each of the subpopulations respond in an opposite way [emphasis added] to administration of stimulant medication (methylphenidate or amphetamine)."

In this connection, it is noteworthy that overdosed favorable responders yielded time-response curves similar to those of adverse responders. This supports a model that places adverse and favorable responders at opposite ends of a continuum with respect to the psycho- 
physiological concept of CNS arousal or activation level. According to this model, stimulant drugs act to increase CNS arousal level, but this results in a 'normalizing' effect on behavior only for those individuals who have an abnormal condition of underarousal in the unmedicated state [emphasis added]. Even in those cases, too much drug may push the patient to the other end of the continuum, resulting in 'overarousal' and thus losing its 'normalizing' effect. This suggests quite distinct underlying disorders of brain function for the two groups of hyperactive children designated as favorable and adverse responders to stimulant medication (pp. 21-22).

According to Swanson (personal communication, 1978), the knowledge of a patient's medical and behavioral history will not identify favorable responders to stimulant medications. He concludes that a method is needed to determine those hyperactive children that are likely to benefit from stimulant therapy before any drug is administered.

\section{Formulation of Hypothesis for Stimulant Drug Effectiveness}

The inability to predetermine the effects of amphetamine, methylphenidate, and pemoline in hyperactive children might be due to the fact that children in past studies were not separated into subgroups. The use of the SCSIT, the SCPNT, and associated clinical observations makes it possible to identify subgroups. The sensory integration differences seen in children may be one important point in preestablishing drug effectiveness.

Ayres' $(14,21)$ work on the depressed-prolonged postrotary nystagmus dichotomy might provide a theoretical explanation for two types of hyperactivity. Ayres' work is similar to the work of Porges (19) and de Quiros and Schrager (20). Porges proposed two models of hy- peractivity: (a) hyperactivity as a compensatory behavior to raise the arousal of a suboptimally aroused system and (b) hyperactivity as a result of defective cortical inhibitory mechanisms. de Quiros and Schrager proposed that restlessness be differentiated from hyperactivity. Restlessness is connected with vestibular-proprioceptive disassociation and depends on postural disinhibition elicited by poor information (internal stimuli). Hyperactivity is more connected with brain dysfunction and depends on motor disinhibition elicited by external stimuli.

Ayres (21) has stated that a lack or short duration of postrotary nystagmus may be interpreted as overinhibition in the vestibular nuclei. The vestibular nuclei are relay stations for sensory input from the vestibular receptive apparatus in the inner ear. Another hypothesis is that an adequate amount of sensory excitation is not reaching the vestibular nuclei. The nystagmic rhythm is induced in the vestibular nuclei located in the brain stem and relayed to the eyes producing the vestibulo-ocular reflex. Too much neuroinhibition acting on the vestibular nuclei involved in establishing this rhythm could reduce both the duration and excursion of nystagmus; the opposite case, too little neuroinhibition, could result in nystagmus of prolonged duration. Ayres (21) has hypothesized that this prolonged nystagmus or hyperresponsivity may be due to an insufficient amount of inhibition acting on the vestibular nuclei. Other neuroprocesses may also be poorly inhibited.

It is possible that a child who has an overinhibition of the lower brain areas (decreased postrotary nystagmus) becomes "hyperactive" in an attempt to compensate for this inhibition, thus allowing the brain to function more optimally. The effect of fast, excitatory vestibular stimulation on the "hyperactivity" in children with depressed nystagmus is a clue. Low nystagmus children are calmed by fast vestibular stimulation, whereas high nystagmus children often show increased activity levels. Conversely, it is possible that the group of "hyperactive" children who have decreased cortical inhibition of the lower brain areas (increased nystagmus) become "hyperactive" because of this lowered inhibition.

Because methylphenidate acts primarily as a lower brain stimulant, the drug may release the inhibition of the lower brain in the depressed nystagmus group, thus allowing these children to function more optimally. These children should be the ones who benefit from a drug therapy regimen. The high nystagmus group (those theoretically having poor cortical inhibition) would only receive more input to their already defective inhibitory system, flooding the cortex with additional signals that could not be properly inhibited and thus increasing hyperactive behavior.

\section{Because methylphenidate acts primarily as a lower brain stimulant, the drug may release the inhibition of the lower brain in the depressed nystagmus group, thus allowing these children to function more optimally.}


Children with this high duration postrotary nystagmus would be expected to be poor responders to stimulant medication.

The purpose of this study is to determine if children's responses to the stimulant methylphenidate (Ritalin) can be predicted from profiles on selected sensory integration tests. The expected main effect of Ritalin is improvement in attention.

\section{Method}

\section{Subjects}

The sample was drawn from a pool of 150 outpatient children at the Hospital for Sick Children, Toronto, Canada. Prior to being selected for this study, they were judged to be hyperactive by their physicians and referred to the hospital's outpatient program for indepth screening using the DSM II or DSM III checklist and the Connors Prevent Teacher Questionnaire. The subjects then had participated in a 21/2-day, doubleblind, Ritalin placebo, PAL procedure designed to determine their responsiveness to methylphenidate.

Thirty boys (15 good and 15 poor responders to methylphenidate) were picked arbitrarily from clinic files by a research assistant. Parents were phoned and asked if they would be willing to participate in a study. They were offered the incentive of an occupational therapy sensory integration assessment (a report of which would be sent to the child's physician) and recommendations to other appropriate services. The sample was biased by the fact that it included parents' acceptance of an occupational therapy assessment; it is possible that the sample selection favored children with more pronounced coordination problems or children whose parents knew more about occupational therapy.

All 30 children were scheduled to take the 45-minute assessment during a one-week period. The night before the testing was to start, a freight train carrying chlorine and propane tank cars derailed, necessitating the evacuation of 300,000 people on the west side of Toronto for the entire week. Of the 30 children, 11 were affected by the accident, which means that 19 were left in the study. One child was eliminated from the final data analysis because he had had a home trial on Ritalin, which was not considered as valid as the $21 / 2$-day PAL assessment. Another child was eliminated because his young age (62 months) placed him too close to the basal age level of the tests creating a basement effect. Seventeen boys ( 9 good and 8 poor Ritalin responders) were used in the study. Their age range was 79 to 136 months, with a mean age of 106.8, standard deviation 15.4.

\section{Procedure}

Subjects were all tested in the off-drug state. The examiner was blind as to which group, good responder or poor, the child was in, and the research assistant arbitrarily assigned testing times. Only one examiner was used. Because plasma half-life for elimination of radioactive methylphenidate has been found to be $7.5 \pm .7$ hours (22), it was decided that children taking Ritalin would only have to skip their morning dose to have the drug completely out of their system. All children were given the following tests:

1. SCSIT tactile tests (23): (a) Kinesthesia; (b) Manual Form Perception; (c) Finger Identification; (d) Graphesthesia; (e) Localization of Tactile Stimuli; (f) Double Tac- tile Stimuli; and (g) Tactile Defensiveness (Observation).

2. Vestibular tests: (a) SCPNT (21); (b) Bruininks-Oseretsky Test of Motor Proficiency Subtest 2: Standing Balance (24); (c) SCSIT: Standing Balance Eyes Open; and (d) SCSIT Standing Balance Eyes Closed.

3. Clinical observations: (a) prone extension position; (b) flexion in supine; (c) symmetrical tonic neck reflex; (d) asymmetrical tonic neck reflex; (e) equilibrium reactions; (f) gravitational insecurity; (g) muscle tone; (h) cocontraction; and (i) reaction to the SCPNT.

\section{Results}

The correlation matrix (significant tests only) is shown in Figure 1. Because there were only 17 children in the study, 18 of the original 22 variables were included in the simple correlation matrix. Cocontraction, supine flexion, and symmetrical and asymmetrical tonic neck reflexes were uncorrelated with the vestibular indicators (21, 25).

Inspection of the correlations reveals that drug response is significantly correlated with SCPNT (.05), equilibrium reactions (.01), Double Tactile Stimuli (.01), and reaction to the SCPNT (.01).

One-way analysis of variance was done with the drug response as the independent variable (see Table 1). Significant differences were found between good and poor responders on the following variables: Double Tactile Stimuli $(F[1,15]=13.93$, $p \leq .01)$; SCPNT $(F[1,15]=5.09$, $p \leq .05)$; equilibrium reactions $(F[1,15]=11.08, p \leq .01)$; and reaction to the SCPNT $(F[1,15]=$ $7.35, p \leq .02)$.

\section{Discussion}

Of interest in the correlation ma- 


\begin{tabular}{|c|c|c|c|c|c|c|c|c|c|c|c|c|c|c|c|c|c|c|}
\hline 8 & 足 & 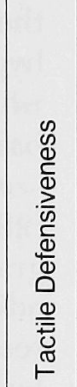 & 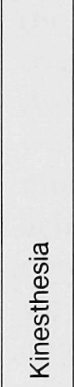 & 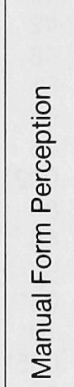 & 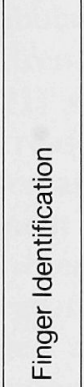 & 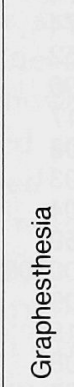 & 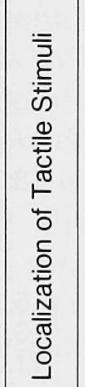 & 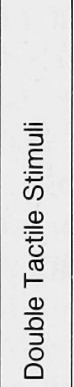 & 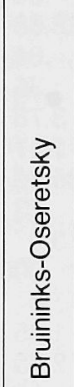 & 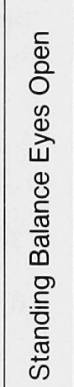 & 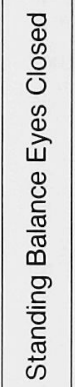 & $\begin{array}{l}\text { 足 } \\
\text { O } \\
\text { o }\end{array}$ & 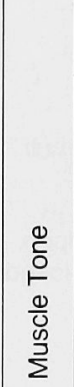 & 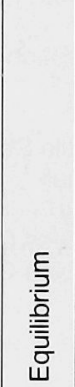 & 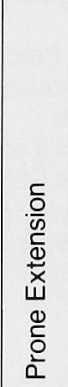 & 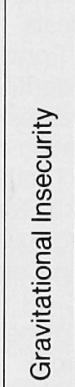 & 芒 & 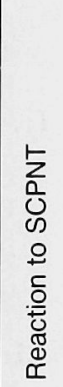 \\
\hline Drug & 1.00 & & & & & & & & & & & & & & & & & \\
\hline Tactile Defensiveness & & 1.00 & & & & & & & & & & & & & & & & \\
\hline Kinesthesia & & & 1.00 & & & & & & & & & & & & & & & \\
\hline Manual Form Perception & & & & 1.00 & & & & & & & & & & & & & & \\
\hline Finger Identification & & & & & 1.00 & & & & & & & & & & & & & \\
\hline Graphesthesia & & & & & & 1.00 & & & & & & & & & & & & \\
\hline Localization of Tactile Stimuli & & & & & & & 1.00 & & & & & & & & & & & \\
\hline Double Tactile Stimuli & .69 & .51 & & & & & & 1.00 & & & & & & & & & & \\
\hline Bruininks-Oseretsky & & & & & & & & & 1.00 & & & & & & & & & \\
\hline Standing Balance Eyes Open & & & & & -.59 & & & & & 1.00 & & & & & & & & \\
\hline Standing Balance Eyes Closed & & & & & & .73 & & & & & 1.00 & & & & & & & \\
\hline SCPNT & -.50 & & & & & & & & & & & 1.00 & & & & & & \\
\hline Muscle Tone & & & & & & & & & & & & & 1.00 & & & & & \\
\hline Equilibrium & .65 & & & .49 & & & & .67 & & & & & & 1.00 & & & & \\
\hline Prone Extension & & & & & & & & & & & & & & & 1.00 & & & \\
\hline Gravitational Insecurity & & .48 & & & & & & & & & & & & .63 & & 1.00 & & \\
\hline Age & & & & & & & -.54 & & & & & & & & & & 1.00 & \\
\hline Reaction to SCPNT & .57 & .49 & & & & & & .52 & & & & & & & & & & 1.00 \\
\hline $\begin{array}{l}.48=.05 \text { level } \\
.56=.01 \text { level } \\
\text { SCPNT, Southern California }\end{array}$ & 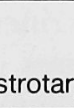 & 政 & 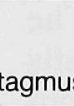 & $T$ & & & & & & & & & & & & & & \\
\hline
\end{tabular}

trix is the group of correlations tying together gravitational insecurity (GI), reaction to the SCPNT, Tactile Defensiveness (TD), equilibrium reactions, and Double Tactile Stimuli (DTS). Three of these tests (TD, GI, and DTS) are thought to measure aspects of functioning mediated mainly by the cortical areas of the brain. The correlation of equilibrium reactions and reaction to the SCPNT with several of the tactile tests is probably due to the contri- bution that both the tactile and balance-vestibular systems make to motor planning (6). Unlike previous findings $(21,26)$, the SCPNT was not significantly correlated with equilibrium reactions or prone extension. However, both SCPNT and equilibrium reactions did differentiate between good and poor responders to Ritalin. Both tests are considered to be indicators of the functioning of the vestibular system. Double Tactile Stimuli indicates immaturity in tac- tile processing; however, as a short diagnostic test, it has low test-retest reliability (.01 to .54 depending on age) (23). With the small sample size, the finding of significance of Double Tactile Stimuli (DTS) may be due to chance. The DTS may also be detecting tactile defensiveness. Because it is given last, after five other tactile tests have biased the child's nervous system by constant light touch, DTS is the most likely of the tactile tests to evoke a tactually defensive response. 
Table 1

One-Way ANOVA Summary Table: Ritalin Good Versus Poor Responders

\begin{tabular}{lcccc}
\multicolumn{1}{c}{ Variable } & DF & MS & $\boldsymbol{F}$ & $\boldsymbol{P}$ \\
\hline Tactile Defensiveness & 1 & .64 & .74 & .40 \\
Kinesthesia & 1 & 28.88 & .74 & .42 \\
Manual Form Perception & 1 & .84 & .52 & .48 \\
Finger Identification & 1 & .36 & .06 & .81 \\
Graphesthesia & 1 & 3.78 & .17 & .68 \\
Localization of Tactile Stimuli & 1 & 2.47 & .09 & .76 \\
Double Tactile Stimuli & 1 & 35.69 & 13.93 & $.002^{\star}$ \\
Bruininks-Oseretsky & 1 & .73 & .04 & .84 \\
Standing Balance Eyes Open & 1 & 313.0 & .59 & .46 \\
Standing Balance Eyes Closed & 1 & .0008 & .00006 & .99 \\
SCPNT & 1 & 377.8 & 5.09 & $.04^{\star}$ \\
Muscle Tone & 1 & 1.65 & 3.15 & .10 \\
Equilibrium & 1 & 2.75 & 11.08 & $.005^{\star}$ \\
Prone Extension & 1 & .55 & .67 & .43 \\
Gravitational Insecurity & 1 & 1.44 & 2.89 & .11 \\
Age & 1 & 279.6 & 1.22 & .28 \\
Reaction to SCPNT & 1 & 6.62 & 7.35 & $.02^{\star}$ \\
\hline
\end{tabular}

* + significant.

ANOVA, analysis of variance. SCPNT, Southern California Postrotary Nystagmus Test.
Results of the analysis reveal that, in this small sample, pooled groups of good and poor responders to Ritalin can be differentiated by their SCPNT duration, equilibrium reactions, DTS scores, and their reaction to the SCPNT. A similar trend is seen in a predictive Cylert study (29). As a group, children with high SCPNT scores, poor equilibrium reactions, low DTS scores, and adverse reactions to the SCPNT were the poor responders to Ritalin. High SCPNT scores are thought to be associated with a cortical inefficiency causing lack of cortical inhibition on the vestibular system (21). DTS is thought to tap higher level tactile discrimination; therefore, low scores may be due somewhat to inefficient cortical processing. In this case, equilibrium reactions were tested using a large (36 in.) beach ball, and they may have reflected automatic equilibrium responses as well as some gravitational insecurity. Adverse responses to the SCPNT are usually of an autonomic nervous system nature (e.g., stomachache, fear, pallor, sweating, increased respiration, eyes rolled back) and are thought to be caused by an intravestibular conflict, that is, conflicting messages from the two divisions of the vestibular mechanism.

The children with the hypothesized lower center inefficiencies (decreased duration postrotary nystagmus and nonaversive reaction to the SCPNT) tend to be good responders to Ritalin. Lower center inefficiencies are theoretically linked to overinhibition. The findings in this study may partly explain how stimulant medications work to calm hyperactivity. Kimball (27) presented a more detailed theoretical explanation. The fact that the vestibular measures of du- ration of nystagmus (SCPNT) and the reaction to the SCPNT discriminate between good and poor drug responders indicates that there may be at least two types of hyperactivity associated with ADD which may be differentiated on the basis of vestibular functioning.

A concurrent predictive study (29) found that children who are gravitationally insecure and have adverse reactions to the SCPNT tend to be poor responders to Cylert. Duration of postrotary nystagmus appears to predict Cylert effectiveness. This same variable also appears to predict Ritalin effectiveness. Therefore, the vestibular measures of reaction to the SCPNT and the duration of postrotary nystagmus as measured by the SCPNT may be primary predictors of drug responsiveness.

A theoretical explanation of how stimulant medication works may be seen in terms of the effect stimulation has on the nervous system of hyperactive children. Drug stimulation of hyperactive children with underaroused-inhibited lower brain centers (decreased postrotary nystagmus and nonaversive response to the SCPNT) may result in increased attention (higher scores on the PAL) (16). The "calming" effect of the medication on good responders could be the result of the children's no longer needing to compensate by unconsciously trying to increase arousal 
to override the inhibition in their lower brain centers. Conversely, drug stimulation of children with deficient inhibition (increased postrotary nystagmus and adverse response to the SCPNT) only increases the amount of input to be inhibited by the already defective inhibitory system, thereby decreasing attention (lower scores on the PAL).

Slight differences in vestibular indicators as predictors of good and poor drug responses were seen between Ritalin and Cylert studies $(27,29)$, although in both cases the vestibular measures were the best predictors. These differences in vestibular predictors may indicate the state of our ability to test the vestibular system as well as our inability to discriminate between the two divisions of the vestibular mechanism. The SCPNT basically measures semicircular canal functions, whereas the clinical observations of gravitational insecurity and adverse reaction to the SCPNT are thought to indicate utricle-saccule functions.

These two different parts of the vestibular mechanism have previously been treated as a single unit in most research and theory. Differentiation of semicircular canal from utricle-saccule functions is possible now only through clinical observations; yet with improvements in technology, the two divisions of the vestibular mechanisms someday might be tested directly.

The finding that two discernible types of hyperactivity can be determined by sensory integrative testing is just a first step in identifying children who are stimulant drug responders. Other differences in central nervous system (CNS) functioning should be investigated, along with other methods (besides the administration of drugs) of dealing with these problems. The effect of using a sensory integration approach in occupational therapy to improve the processing of the vestibular system in hyperactive children needs to be assessed. Ayres (21) showed that children with decreased postrotary nystagmus increased their academic achievement more than matched controls when they were given sensory integrative occupational therapy (aimed at normalizing vestibular functioning) rather than special education. It might be possible to decrease hyperactivity in the good responders to medication by increasing the efficiency of their vestibular systems through sensory integrative occupational therapy, thereby eliminating or altering the need for stimulant medications.

Kimball (28) found that vestibular indicators did not change when the good responders were given Ritalin, which indicates that Ritalin is not actually influencing the vestibular system, but is treating the symptoms of hyperactivity. These conclusions are related to the observation that hyperactive children do not "outgrow" their need for stimulant drugs but, in fact, may even profit from them as adults.

\section{Conclusion}

Now that types of sensory integration deficits in hyperactive and/ or learning disabled children can be differentiated, these subgroup breakdowns should be applied to other research with the ADD population. Perhaps the lack of significant outcomes in studies with learning disabled children is due to the failure to differentiate between subgroups, which means that findings were further obscured through pooling of data. Also involved is the treating of symptoms rather than of underlying causes and the attempts to treat underlying causes by professionals untrained in occupational therapy sensory integration theory and methods. Occupational therapists must individualize sensory integrative treatment. Unlike skill training that relies on practice to develop one set of predictable responses, therapeutic activities first must stimulate the brain to organize itself and then facilitate spontaneous appropriate adaptive responses.

Sensory integration tests and clinical observations need to be researched more fully, and their theoretical bases need to be expanded so that occupational therapists will be better able to understand what aspects of the CNS they are assessing and how these assessments relate to each other. Occupational therapists and others using sensory integrative testing and motor assessments need to realize the incredible complexity of the parameters they are attempting to measure. They also need to understand that they are only at the frontier of explaining interrelationships. Although therapists are now better able to predict adverse responses to stimulant medication, this is not a cause and effect relationship, and the complexity of the interrelationships needs to be respected. Perhaps with future research, these relationships and the reasons behind them will be clarified.

\section{ACKNOWLEDGMENTS}

The author thanks Dr. William Meyer, Syracuse University, who served as project consultant; Dr. Edward O'Connell, Syracuse University, who served as statistical consultant; Drs. William Logan and James Swanson, Hospital For Sick Children, Toronto, who supplied subjects; and Rosalie Sabler-Nadler, OTR, and Margaret Flintoff, who served as unpaid research assistants. Partial support was provided by a grant from the Center For The Study of Sensory Integrative Dysfunction. This arti- 
cle is based on a dissertation submitted in partial fulfillment of requirements for a doctoral degree from Syracuse University, Syracuse, New York.

\section{REFERENCES}

1. Sroufe LA: Drug treatment of children with behavior problems. Review of Child Development Research, Vol. 4. Chicago: University of Chicago Press, 1975, pp 347-407

2. Kinsbourne M, Swanson J, Herman D: Laboratory Measurement of Hyperactive Children's Response to Stimulant Medication in Minimal Brain Dysfunction: A Developmental Approach, E Denoff, Listern, Editors. New York: Masson, 1979

3. Frostig M: Developmental Test of Visual Perception. Palo Alto, CA: Consulting Psychologist Press, 1961

4. Kephart NC: The Slow Learner in the Classroom. Columbus, $\mathrm{OH}$ : Charles Merrill, 1960

5. Ritter DR, Sabatino DA: The effects of method of measurement upon children's performance on visual-perceptual tasks. Journal of School Psychology 12:296-304, 1974

6. Sabatino DA, Ysseldyke JE, Woolston $\mathrm{J}$ : Diagnostic prescriptive perceptual training with mentally retarded children. Am J Ment Defic 78:7-14, 1973

7. Sabatino DA, Ysseldyke JE: Effects of extraneous background on visual-perceptual performance of readers and non-readers. Percept Mot Skills 35:323328,1972

8. Cruickshank W, Hallahan DP: Perceptual and Learning Disabilities in Children. Syracuse, NY: Syracuse University Press, 1975

9. Ayres AJ: Patterns of perceptual-motor dysfunction in children: A factor analytic study. Percept Mot Skills 20:335368,1965

10. Ayres AJ: Interrelations among perceptual-motor abilities in a group of normal children. Am J Occup Ther 20(6):288-292, 1966

11. Ayres AJ: Interrelationships among perceptual-motor functions in children. Am J Occup Ther 20(2):68-71, $1966 \mathrm{a}$

12. Ayres AJ: Deficits in sensory integration in educationally handicapped children. J Learn Disabil 2:160-168, 1969

13. Ayres AJ: Characteristics of types of sensory integrative dysfunction. Am J Occup Ther 25(7):329-334, 1971

14. Ayres AJ: The Effect of Sensory Integrative Therapy on Learning Disabled Children: The Final Report. Pasadena, CA: Center for the Study of Sensory Integrative Dysfunction, 1976

15. Ayres AJ: Sensory Integration and Learning Disorders. Los Angeles: Western Psychological Services, 1972

16. Swanson J, Barlow A, Kinsbourne M: Task specificity of responses to stimulant drugs in laboratory tests. Int J Ment Health 8:67-82, 1979

17. Swanson JS, Kinsbourne M, Roberts W, Zucker K: Time-response analysis of stimulant medication on the learning ability of children referred by hyperactivity. Pediatrics 61:21-29, 1978

18. Swanson JM, Kinsbourne M: Cognitive effects of stimulant drugs on hyperactive children. In Attention and Cognitive Development, GA Hale, M Lewis, Editors. New York: Plenum Publishing Corporation, 1979

19. Porges SW: Peripheral and neurochemical parallels of psychopathology: A psychophysiological model relating autonomic imbalance to hyperactivity, psychopathy, and autism. Advances in Child Development and Behavior, Vol II. New York: Academic Press, 1976

20. de Quiros JB, Schrager OL: Neuropsychological Fundamentals In Learning Disabilities. San Rafael, CA: Academic Therapy Publications, 1978

21. Ayres AJ: Southern California Postrotary Nystagmus Test. Los Angeles: Western Psychological Services, 1975

22. CIBA, Bioavailability data-Ritalin hydrochloride (methylphenidate hydrochloride USP), Summit, NJ: CIBA, 1976

23. Ayres AJ: The Southern California Sensory Integration Tests. Los Angeles: Western Psychological Services, 1972

24. Bruininks R: Bruininks-Oseretsky Test of Motor Proficiency. Circle Pines, MN: American Guidance Service, 1978

25. Ottenbacher K: Excessive postrotary nystagmus duration in learning disabled children. Am J Occup Ther 34:4044,1980

26. Ottenbacher K: Identifying vestibular processing dysfunction in learning disabled children. Am J Occup Ther 32:217-221, 1978

27. Kimball JG: Hypothesis for prediction of stimulant drug effectiveness utilizing sensory integrative diagnostics, 1985 . $J$ Am Osteopathic Assoc, to be published.

28. Kimball JG: Differences in performance on sensory integrative measures on and off stimulant medication $\mathrm{Ri}$ talin. Occup Ther J Res, to be published

29. Kimball JG: The use of sensory integrative diagnostics to predict hyperactive children's responsiveness to methylphenidate (Ritalin) and pemoline (Cylert) (Doctoral dissertation, Syracuse University, 1980). Dissertation Abstracts 
Copyright of American Journal of Occupational Therapy is the property of American Occupational Therapy Association and its content may not be copied or emailed to multiple sites or posted to a listserv without the copyright holder's express written permission. However, users may print, download, or email articles for individual use. 